\title{
How do gym members engage with music during exercise?
}

\section{Rachel Hallett and Alexandra Lamont}

Centre for Psychological Research, Research Institute for Social Sciences, Keele

University, Newcastle-under-Lyme, UK

Corresponding author:

Rachel Hallett

Centre for Psychological Research

Keele University

Keele

Staffordshire

ST5 5BG

Tel: 01782733934

Email: r.j.hallett@keele.ac.uk

Rachel Hallett is based at Keele University, researching the potential for music to help facilitate exercise adherence. She has postgraduate qualifications in both music and psychology, and previously worked as an exercise to music teacher, gym instructor and personal trainer.

Alexandra Lamont is a senior lecturer in music psychology at Keele University. She has studied and taught in the fields of music, education and psychology, has expertise in developmental psychology and research methods, and is interested in ths sociology and psychology of music consumption and engagement with musical activities. 


\title{
How do gym members engage with music during exercise? A thematic analysis
}

\author{
Music is widely used to accompany exercise and research has investigated its \\ effects on a range of physical, physiological and psychological outcomes using \\ quantitative methods. This research sought to investigate music and exercise \\ using a qualitative approach. Gym members were interviewed about their \\ exercise and music use while at the gym ( $n=16$, age range 17-67, $M=44.6)$. \\ Through thematic analysis, we found two distinct groups of exercisers, \\ "socialisers" and "workers", who engaged differently with other people and with \\ the gym environment, and showed contrasting use of music while exercising. \\ "Socialisers" were largely ambivalent towards music for exercise, while \\ "workers" displayed sophisticated tailoring of playlists to facilitate increased \\ effort. The finding that there are two types of engagement with with both others \\ and music use is novel, and merits further research to understand how life stage \\ and age may be influencing exercisers' tendency to reflect one or the other \\ category. In contrast with existing literature, a liking for contemporary styles was \\ found among exercisers in their 40s and 50s. The findings suggest a strong \\ influence from developments in music technology on the use of music in \\ exercise, with important implications for exercise facility managers who wish to \\ make their premises appealing across the lifespan.
}

Keywords: motivation; physical activity; health behaviours; Mp3; lifespan

\section{Introduction}

Regular exercise is well-established as beneficial for both physical health (Myers 2008, Powell et al. 2011) and mental health (Deslandes et al. 2009, Donaghy 2007). Many people accompany their exercise activities with music, either in the context of an exercise-to-music class, through the use of personal listening devices or by listening to music through leisure centre PA systems. In recent years there has been an expansion of research in the field of exercise music, and evidence is converging to show that music has positive effects compared with a no-music control (Terry and Karageorghis 
2006). Specifically, the benefits identified include increased pace from music with increased tempo (Edworthy and Waring 2006, Waterhouse et al. 2010), and increased stamina with motivational music compared with oudeterous (neither motivational nor demotivating) music (Karageorghis et al. 2009). Even in circumstances such as high intensity exercise, where music does not appear to benefit performance, participants report that music enhances their enjoyment and their tolerance of effort and motivates them to continue the activity for a longer duration of time (Tenenbaum et al. 2004). Karageorghis et al. (1999) suggested that music’s motivational qualities can help control arousal levels, reduce feelings of exertion and improve mood, and may be a factor in adherence. There has, however, been little study of whether music has benefits beyond those relating to exercise variables such as stamina and pace. Tenenbaum et al.'s (2004) participants' feedback suggests music may enhance the overall exercise experience by creating a pleasant environment for exercise activities, and music's influence on exercise enjoyment is worthy of further investigation.

Factors influencing motivation to exercise are many and varied, as outlined by Sherwood and Jeffery (2000), whose consideration of exercise environments focuses on accessibility and available time rather than the appeal of the environment. Humpel et al.’s review (2002) again identified accessibility as correlating with physical activity, but also finding that the aesthetics of the exercise environment influenced exercise behaviour. Fox identified a “feeling good effect of exercise” (1999, p.414), suggesting positive affect may be a benefit of exercising, further supported by McAuley et al. (2003), who found maintaining exercise in the long term depended particularly on positive affect during exercise and also on social support. However, widely-used health behaviour models such as the Theory of Planned Behaviour (Ajzen 1991), Transtheoretical Model (Prochaska and DiClemente 1982) and Health Action Process 
Approach (Schwarzer 2008) ignore positive affect in favour of a focus on rational decision-making, sense of competency and evaluation of a behaviour as beneficial, from one's own and others' perspectives. Enjoyment of a health behaviour is excluded in this approach, possibly because such models relate to health behaviours which would not normally be associated with enjoyment (taking medication, for example).

The emphasis in existing research has been on enhancing sporting performance through facilitating increased intensity or stamina in training, with much of the research activity involving young adult participants (typically undergraduates) with high levels of fitness in laboratory settings (e.g. Crust and Clough 2006, Elliott et al. 2005, Karageorghis et al. 2009). Some researchers have looked at the other end of the lifespan with gerontological studies of possible applications of music in physical activity in later life (Becker et al. 1995, Barnett et al. 2003).There is little research that has looked across a broad age range, despite fitness facilities often having members ranging in age from their teens to their 70s and beyond attending at the same time. Isolating narrow age groups does not reflect the reality on the gym floor, and a study gathering data from participants of widely varying ages and backgrounds offers the scope to compare their exercise music use and preferences.

Studies of music preference in everyday life indicate that tastes are formed in adolescence and young adulthood (Holbrook and Schindler 1989) and a study by North (2010) looking at a variety of demographic variables and individual differences found that of all the variables, age was mostly closely related to musical style preference. Yet Lamont and Webb (2010) found preferences shifted in both the long- and short-term, with listeners having current and all-time favourites and refreshing their listening material regularly; this indicates a dynamic process of music preference in everyday life. 
The music in exercise music studies is usually selected for participants by researchers, and occasionally rated by participants’ peers (Elliott et al. 2005, Karageorghis et al. 2006). In the rare studies where participants self-select music (Bharani et al. 2004, Bishop et al. 2007, Potteiger et al. 2000), little is known regarding their choice of music and reasons for making it. There are assumptions that preference for exercise music is age-related: Priest and Karageorghis (2008) suggested that music played over gym PA systems should include tracks from a range of eras to reflect the various ages of the exercisers. Karageorghis et al. (2006) emphasised the importance of sociodemographic variables for music preference, and their relationship with style, release date and performer. It is not known whether exercisers' music choices reflect their age when they are able to choose their own music.

A few studies have mentioned exercisers' music choices in the context of everyday music-listening practices. In Bull’s large-scale iPod study, one participant described how 'I also like really upbeat, dance-style music. This is good not only for the gym, but also when I’m just walking around the city’ (2007: 29). One of Heye and Lamont's participants (2010) described playing upbeat rock music as he walked to the campus sports centre for a workout (the study examined portable listening device use while walking/travelling, rather than during exercise). The reference to 'upbeat' music in both studies supports the suggestion in a recent literature review that tempi of 125140 beats per minute (bpm) are ideal for non-synchronous exercise (Karageorghis and Priest 2012): this suggestion appears to be related to heart rate, although exercisers’ preferred bpm in the cited literature varied. This tempo corresponds with the dance styles found in nightclubs, also associated with physical movement. Priest and Karageorghis (2008) mentioned some elements of self-selection in their qualitative study, but focused primarily on responses to music in classes and on gym PA systems: 
they noted, nevertheless, that facilitation of music self-selection during exercise should help maximise motivational benefits although the reasons for this are not made clear. There is clearly scope to expand this limited knowledge by exploring exercisers' autonomous use of music; (what music they choose to listen to if they are able to selfselect, using devices such as iPods and MP3 players), and how they use that music while exercising.

This study seeks to address the lack of knowledge regarding autonomous use of music in exercise. Since ageing is typically associated with a decline in exercising (Health and Social Care Information Centre 2010), it is particularly important to be able to encourage exercise maintenance beyond adolescence and early adulthood. An understanding of motivation and the potential of music to enhance it offers scope to do so. A qualitative approach using semi-structured interviews enabled flexible exploration of exercise motivations and the way in which music was used (or avoided) in order to realise these, and we aimed to recruit participants across a broad age range, with a variety of backgrounds. To achieve this, we carried out the study through interviews at a local authority gym which had a membership from a broad demographic (private health clubs may be more exclusionary due to higher-priced memberships) and also had a remit for promoting community fitness through being a public sector facility rather than being privately run.

\section{Method}

Sixteen members of a local authority gym in the West Midlands area of the United Kingdom were interviewed using a semi-structured framework. Fifteen of the participants had been using the gym regularly for at least a year, while one (female, aged 57) had recently returned to exercise after a period as a carer. The interviews were 
carried out on a one-to-one basis with one exception: two women, aged 48 and 52, were interviewed together for practical reasons, and to enable shared reflections because they exercise together. Table 1 shows participant information.

Table 1. Participant information (all names are pseudonyms).

\begin{tabular}{lccllccl}
\hline Name & Gender & Age & Employment & Name & Gender & Age & Employment \\
\hline Lucy & F & 17 & Student & Karen $^{\mathrm{a}}$ & $\mathrm{F}$ & 48 & Full time work \\
Craig & $\mathrm{M}$ & 22 & Full time work & Elaine $^{\mathrm{a}}$ & $\mathrm{F}$ & 52 & Full time work \\
Ben & $\mathrm{M}$ & 23 & Jobseeker & Carol & $\mathrm{F}$ & 54 & Full time work \\
Matthew & $\mathrm{M}$ & 24 & Full time work & Linda & F & 57 & Full time work \\
Emma & $\mathrm{F}$ & 32 & Full time work & Martin & $\mathrm{M}$ & 60 & Retired \\
Robert & $\mathrm{M}$ & 39 & Full time work & John & $\mathrm{M}$ & 62 & Semi-retired \\
David & $\mathrm{M}$ & 43 & Long term sick & Barbara & F & 65 & Retired \\
Nigel & $\mathrm{M}$ & 48 & Full time work & Margaret & F & 67 & Retired \\
\hline
\end{tabular}

Average age: 44.6 years ( $\mathrm{SD}=16.6$ years)

${ }^{\mathrm{a}}$ Interviewed together .

${ }^{\mathrm{b}}$ Asked not to be directly quoted.

Participants were recruited through direct approach at the leisure complex, and interviews were carried out on-site, in a seating area near the reception when the facility was quiet, and in a separate meeting room in another part of the facility when the seating area was busy. The interview schedule was developed to explore individuals' exercise habits, preferences and aims, and how they used music, television (integrated into the gym's machines) and social interaction while they exercised. This included questions to explore a range of aspects of exercise behaviour reflecting and extending current ideas in literature. Participants were asked about their perceptions of what might and might not constitute motivational music for exercise, whether they were conscious of synchronizing to the beat of music while exercising, and about their specific 
preferences, discussed in the context of the music the gym played over the PA system. Participants were also asked about their reasons for attending the gym, and their preferred fitness activities. Interviews were recorded on an Olympus VN-4100 digital recorder and transcribed using Express Scribe software.

Prior to the interviews, ethical approval was obtained from the authors’ university and informed consent was obtained from participants. All participants were advised that they would be referred to by pseudonyms in order to preserve their anonymity, and all but one participant gave permission to be directly quoted in research reports.

Data were analysed using thematic analysis based on Braun and Clarke’s sixstage framework (2006) because of its flexibility and potential to deliver rich and complex understandings. Following familiarisation with the data through reading and transcription, the data was coded, developed into an unrefined map of codes and themes, further refined through continued reading and analysis, moving forwards and backwards through the six stages. Themes were identified at a semantic level, recognising the concepts directly communicated by participants, although consideration was given to possible deeper, latent concepts.

\section{Findings}

Two main themes relating to music use were identified. The first, 'Environmental engagement,' related to the extent to which members engaged with their surroundings while exercising, particularly other people. Members could be categorised as belonging to one of two main types: 'socialisers,' who engaged extensively with the gym and other people and who were ambivalent towards music, and 'workers,' who preferred to disengage from their surroundings and other people, listening to their own music and 
sometimes using this as a barrier to social contact. The second theme, 'Focus and dissociation,' concerns how music was used in relation to the actual exercise activities, with members again reflecting one of two main types: those who wished to focus on their activity using music to maximise workout quality (who tended to be workers), and those who dissociated from their activity through chatting and watching TV to reduce perceived effort (who tended to be socialisers). Quotations are referenced by participant pseudonym and age.

\section{Environmental engagement}

For those who were in employment, the gym was somewhere to 'switch off,' disengaging from the environment and in particular from other people. For instructors such as Craig, at higher risk of being interrupted by members for advice, headphones sent a clear signal of being unavailable:

Craig: I use an MP3 or use an iPod, erm, just put my own music on and that really, and that's so, erm, so I'm not interrupted [laughs] so even if it's battery low I put my earphones in ...

Researcher: When you say so you're not interrupted is that, erm, with the members?

Craig: Just with being a gym instructor. (Craig, 22)

Carol, in full time work, was emphatic that the gym did not fulfil a social purpose for her, but did not actively avoid others in the way Craig did:

Interviewer: when you come in how important is it for you to meet up or chat with other people while you're working out?

Carol: Not at all, not at all [laughs]

Interviewer: You had your headphones on, everyone seemed to have their headphones on this morning 
Carol: No, I don't er come to socialise at all. I mean I do sit and talk to people that I know that go there that come in by and by, but I don't come in for a chat [laughs] (Carol, 54)

Carol interacted with other members when approached, although she preferred to listen to music while exercising.

For those not in regular employment, there was a much greater engagement with others. Margaret emphasised the social aspect of going to the gym, and described the steps she had taken to maintain a social network after retirement:

I do find, I don't know if this is any help, the social thing as well. That was one of the other main reasons I went to the [charity shop] because you're socialising, meeting people and talking...it sort of gets to the person you usually talk to, cos we're all the time, moving round different things but, er, and then other time you're standing next to them so you're chatting. I've actually met some really nice people. (Margaret, 67)

For David, aged 43, who was forced to give up his job through sickness, the gym also had a social purpose: he described how 'I still like to meet people and I know everybody now.' For David, the main benefit of the gym, beyond lowering his health risks, was ‘Just getting out my flat for a couple of hours and meeting people.’ He was well-known and liked by other members, and was mentioned specifically by Martin who was retired:

I look forward to seeing David...I think the gym to him is such an important part of his life, it really is... yeah. I see people on a regular basis. (Martin, 60)

For Margaret, David and Martin, the gym was a place to socialise; Beck et al. (2010) found similar motivations to take part in physical activity in their study of retired 
people. The social connections these participants discussed demonstrate how the gym space functions differently for those who are not working compared to those who are: there may be a greater need to engage to replace the social benefits of work. Wearing headphones would impede social interaction, and so these 'socialiser' participants did not use personal music players.

Ben, an unemployed male in his early 20s, fell somewhere between the retired and employed group in terms of background, having not yet found a job following completion of his degree. He sometimes attended the gym on his own, in which case he brought an MP3 player on which he chose to listen to rap, while at other times he worked out with a group of friends using resistance equipment. Ben did not give social interaction as a motivation to attend the gym; rather, he found exercise helped general well-being:

When I have a couple of weeks out, I feel bad. I feel weak, I feel drained and just demotivated in every aspect really...not just fitness but everything else in my life. If I'm feeling good, I perform well in other areas. (Ben, 23)

As well as not fitting into either the employed or the retired categories of gym member, Ben's activities also had elements of the employed's retreat into music, and the retired group’s socialising.

For the retired/long-term sick group, there was a strong theme of interaction with the environment and others, while for employed participants, there was a strong sense of withdrawal and detachment, along with the creation of a separate environment for the self through headphone use. Ben had established social networks outside the gym and these friends sometimes came with him to the gym: the gym extended his social space, rather than creating an environment to build new social connections, and 
was also a place to focus on exercise using a particular style of music (rap) that he found beneficial.

To summarise, the participants tended to fall into one of two categories, 'socialisers' and 'workers.' The socialisers were generally not in employment and liked to engage with others, as in the cases of Margaret, David and Martin, while workers were usually in employment and preferred to engage with their own music, as in the cases of Craig and Carol, sometimes - as in Craig’s case - using personal listening devices as a barrier to others.

\section{Focus and dissociation}

The contrasts in use of gym space and social engagement appear to have a direct impact on the use of music in the gym. For those in the 'worker' category identified in the previous section, a pattern was found of sophisticated use of playlists for workouts, and rejection of much of the music played through the PA system as unsuitable for workouts because it was found insufficiently stimulating:

I find that the music that you play in the gym is just so, it's a bit soporific, it makes you go to sleep a bit. It's not motivational at all. So I've got, erm, the old dance music on there [MP3 player]. (Carol, 54)

Carol's antipathy towards the gym music was echoed by Ben, who was much younger:

Some of the music that comes on is totally inappropriate for the gym. It's not really I don't know. A lot of the James Blunt stuff. It's just so demotivating, when you hear that stuff. You just don't want to do anything...it just chills you out and that's not what you want when you're in the gym. (Ben, 23) 
Carol and Ben brought their own music to the gym in order to satisfy their requirement for a stimulatory effect from their exercise music, and a number of participants referred to their exercise music preferences as 'upbeat.' This relates to findings in previously-mentioned literature (Bull 2007, Heye and Lamont 2010, Karageorghis and Priest 2012): dance music, as listened to by Carol and several other participants, is typically $130-140 \mathrm{bpm}$, falling within the $125-140 \mathrm{bpm}$ range suggested as ideal for non-synchronous exercise (Karageorghis and Priest 2012) due to an empirical link with typical exercising heart rates.

Use of MP3 players offered control of music choice to members, and these generally concerned motivation, described by Emma:

It's not that I dislike the radio. I don't listen to it usually because you never know what's coming on the radio and I know the music that's on my iPod so I know that it's going to get me motivated. (Emma, 32)

Additionally, gym members wanted to boost effort through appropriate music across a wide age range: Linda, 57, described a liking for dance music, and this was frequently mentioned among participants in their twenties to their fifties as being particularly appropriate for cardiovascular activities (treadmills, cycles and other machines where large repetitive movements provide an aerobic workout):

I do like working out to music though. I like dance music. Although I'm 57, I'm very much into house music. I like dance music a lot, and that does make me work out better. (Linda, 57).

Linda’s reference to her age indicated she considered her preferences unusual among her contemporaries, or that they might be perceived to be so, but Carol, 54, also 
described a preference for dance music during cardiovascular activity. For weights, Carol listened to music from contemporary heavy metal bands such as System of a Down and Linkin Park, describing how she felt the style of music encouraged her to work harder:

I feel more powerful when there's something heavy on, don't you, it makes you feel a bit more, I don't know, I think, the really strong ones, the really hard ones I've got on the MP3, they make me feel like, you know, motivate, they're a bit, you know, stronger. (Carol, 54)

Heavy metal and rap were mentioned by other participants as particularly suited to working out with weights. Gym members described focussing on musical factors rather than associations or memories, choosing from their preferred music styles but also selecting particular tracks for the perceived effect of their intrinsic qualities. Although cultural factors and associations were central to Karageorghis et al.’s conceptual model (1999), the participants in this study did not mention them. It is possible that these were also influencing music choice, but participants preferred to describe their selection in terms of its intrinsic qualities benefitting their exercising intensity.

Several participants noted that their choice of music for the gym was a little different from their usual listening at home, emphasising selecting it specifically for exercising. Emma's comments suggested that the music she chose for the gym was more arousing than her usual home listening:

It's the sort of thing that I'd go out to a pub or to a club and find that's the kind of music that I like to listen to when I'm out, not necessarily just at home, yeah, just sort of more easy listening at home. (Emma, 32) 
Ben, 23, said he preferred heavy rock and rap for the gym, describing the music he listened to outside the gym as more varied. He stated that the type of music was more important when exercising than when listening in other contexts, where music was selected 'Just if I like it' (Ben, 23). In the gym, however, it was important that music had a constant beat, hence Ben's previous criticism of 'demotivating' music played over the PA system.

Only two of the participants expressed strong liking for some of the music played in the gym, and engaged with it (at the time, Smash Hits Radio was the default choice for the gym's PA system). They were female, aged 48 and 52, who exercised together and were interviewed together. For them, much of the music reflected shared preferences and provided a vehicle for social connection:

Elaine: I quite like it.

Karen: Yeah, I like it. A bit of background stuff, but when they put the-

Elaine: Dance music on, that's a bit-

Karen: You know the one with 'bumf, bumf, bumf-'

Elaine: When we first went in tonight.

Karen: When it's all mixed up, then I'm OK with it, but when it gets to that, it does like get to me a bit.

Researcher: So it's more the radio, the chart stuff you'd-

Elaine: Yes, yes, yes if I'm honest.

Karen: We sing along sometimes.

Elaine: Yes, we do. We did, move it, move it, move it tonight.

Karen: And sometimes we like 'who let the dogs out', we'll do that.

(Karen, 48, and Elaine, 52)

Karen and Elaine emphasised their liking for contemporary music - as did Carol and Linda, both in their 50s. This seems to contradict earlier findings highlighting the importance of age in influencing general (as opposed to exercise-specific) music 
preferences (Holbrook \& Schindler 1989, North 2010). Participants in the current study found new music and used it in their workouts, suggesting preferences are dynamic, as found in other recent research into general listening (Lamont \& Webb 2010). This challenges the suggestion that gym music should reflect a variety of eras in keeping with exercisers’ ages, which arose in part through interviews with exercise-to-music class instructors (Priest and Karageorghis 2008), and may not apply in the gym.

Karen and Elaine's responses indicate a third group between the workers and socialisers, who we might refer to as 'groupers,' using music as part of a shared identity and for its motivational qualities. This was also implied by Robert who described a group of members working out with weights asking for Kerrang! Radio (heavy rock/metal) to be played in the gym: again, shared preferences and identity as a group were evident, and the Kerrang! style of music was associated by Ben and Carol as suited to resistance exercises.

Music in exercise was important for the workers and groupers. The socialisers, however, expressed little interest in music for exercise, either via the PA system or using their own MP3 players. David, aged 43 and long-term sick, when asked if he ever used headphones during exercise, responded: “No. Very, very rare. I know I can listen to music there but I listen to the main radio.” Martin, aged 60 and retired, echoed this: “I don’t listen to music. I don’t bring an iPod or anything along.”

The socialisers were also not engaging with the music played over the PA system which they often found too loud and said was not music they would normally choose to listen to.

I'm not keen on that [the radio] sometimes. It's too loud and you know it's not my, erm, my sort of music. I don't mind it so much, but sometimes you come in and it's blaring. (Martin, 60) 
Unlike the younger members, the gym's choice of music was rejected as 'not my thing' rather than for being unsuitable for exercise. Excessive volume was commented on by several of the retired members, including Barbara:

Just before Christmas I went back out and asked if they could turn it down. I mean to me it should be back, it should be background music. I do listen to it. I don't dislike it because David always says to me "Oh, you complaining about the music again? It's good.” And I say, “Yes music is good, but I don't want to walk in and have it blasted at me as if I'm in a nightclub.” It's not a nightclub. So I'll probably go out and ask them to turn it down. (Barbara, 65)

This may indicate that the way in which these individuals interacted with the environment and others was compromised by the volume and/or style of music and their perceptions of its suitability. For Martin, this was more personal ("not my sort of music”), but even when not disliked, as in Barbara's case, the music was preferred as a background element rather than a focus.

John, who was semi-retired, described the perception that gym music was aimed at a younger cohort:

I would say up to sort of erm, up to 30, 35-ish is generally what I would say it's pitching at, but I, sometimes I hear it and sometimes I don't so maybe there is other times I mean if I don't like it I can switch it off anyway, internally sort of, switch it away. It's not bad, don't get me wrong, it's not bad music, erm it's bubble gum. (John, 62)

There was not an outright rejection of the idea of exercising to music, however. Margaret acknowledged that some gym members might find it helpful: 'I'm sure it does [help] with a lot of people, you know, background music’ (Margaret, 67). This suggests a position where music was not considered pertinent to one’s own workouts, but was 
recognised as a potential tool that others might find useful, reflecting the positioning of the self as a non-music user in an environment where many people like to listen to music.

Taking these comments in conjunction with those from members in their twenties, it appears that older members are not catered for by the music (and may not wish to be), but neither are those who they feel it is aimed at. Of all sixteen interviewees, the only two expressing a particular liking for the gym music were Karen and Elaine, aged 48 and 52.

The younger participants addressed their dissatisfaction with the gym's music by bringing in their own on MP3 players and similar devices. The older participants owned devices but did not seem to have the same attachment to them as the younger participants: 'I mean I have got it, a player but as I say it's easier just to plug in and look at it the television' (Barbara, 65). Indeed, among this group it was more common to listen to the televisions integrated into the cardiovascular machines despite the possibility that this might compromise social interaction. Television use was related to dissociation, as described below by semi-retired John:

But the TV screens sometimes like today, there was, there was one of these auction type programmes on and I just caught into something on gold rings and things which just interested me, suddenly find I've done 5 minutes without realising I've done 5 minutes. (John, 62)

Talking to other members was another way of dissociating: 'It's company. You've got company... I find talking to somebody time goes quicker' (David, 43). The TVs provided an alternative if needed, with the implication that exercise by itself was onerous and that something was needed alongside to make the experience more positive, and that talking was preferable to listening to the TVs: 
But it is like more interesting if there's nobody to talk to you've got the television, so you can just watch it, the television...to make the time go more quickly.

(Margaret, 67)

People talking on the TV presented a 'next best' substitute for when nobody was available in the gym to talk to. Barbara echoed Margaret's comments on the TV:

\begin{abstract}
It passes the time, you don't realise, do you, how long, and it, if you've got on it and you're a bit stiff and it's hard work. If you're listening to I don't know, I sometimes have the chefs on and I'm looking at the recipes, you don't realise then, how much you're doing, and I think you forget then that it's ... a distraction, yeah, you don't realise that you're putting in more the effort and the pace in to go then.
\end{abstract} (Barbara, 65)

Barbara's comments referred to discomfort while exercising, and there is some evidence that music as a distractor can be a pain-reliever, although the effect is small (Cepeda et al., 2009).

For younger gym users, the TVs were rejected because they preferred not to dissociate. While Barbara’s comments suggest that she believed she maintained a good pace even if distracted, Craig felt the opposite:

On the bike and that mainly, it's like a distraction, isn't it? If you're watching the telly then you might not be going as fast you know, trying to watch your pace and stuff so no, I don't watch the telly. (Craig, 22)

The application of music to workouts again demonstrated a divide between the two previously-identified groups, with workers more focused on workout quality and the application of music to achieve this and socialisers looking for engagement with 
others, often dissociating from the exercise itself, and with more ambivalence towards music.

\section{Discussion}

This study investigated motivations and music use in the gym among members of a local authority leisure complex, reflecting a range of ages and backgrounds. Two main themes were identified. The first theme, 'Environmental Engagement' suggests that regular gym attendance is either a way of switching off from one's surroundings to focus on physical activity, or that physical activity provides a way of satisfying the need for social contact which music does not play a part in. These two types of exerciser are named 'workers' and 'socialisers' respectively, reflecting how each group engaged with exercise, other members, music and the gym environment, and also because workers tended to be in employment.

There were variations within the worker group, with some willing to interact with people they knew, despite preferring to listen to their music, while for others, headphones provided a barrier without having to 'blank' others, which would be considered rude. A similar example is found in Michael Bull's study of iPod culture in urban environments, where his participant Fred used his headphones to avoid talking to a colleague, not through dislike, but because 'commute time is the only real private time I get’ (2007, p.58).

There is clear evidence of a third group falling somewhere in between the two: 'groupers,' who use music heard through a PA system as a way of connecting socially with exercising friends and acquaintances. This group is worthy of further exploration, and research with those who attend exercise classes may shed further light on the complex ways in which people engage with their exercise activity, music, entertainment and others around them. 
The second theme, 'Focus and Dissociation,' relates to the way in which music is used to focus on exercise activity, or rejected in favour of chatting or listening to the TV in order to 'switch off' from the activity. Workers tended to fall into the 'Focus' category while socialisers were more likely to use non-musical distractions to dissociate from their exercise activities. The socialisers described exercising for longer while dissociating, either through talking or listening to the TV. The workers did not mention music assisting stamina, but rather associated it with helping facilitate higher intensity. This is consistent with Tenenbaum et al.'s findings (2004). Because of the qualitative nature of this study, no measurements of actual output were taken, and these participant observations are based on their own perceptions.

While the background music was not problematic for the socialisers, it was important that it was not too loud. Given that the majority of the workers preferred their own music to that played by the gym, and brought portable music players, again volume is potentially an issue because of the volume needed through headphones to override the sound of the PA system, and potential safety implications of this (Hodgetts et al. 2009).

The suggestion that music should reflect exercisers’ ages (Karageorghis et al. 2006, Priest and Karageorghis 2008) was not well supported, with exercisers in their 50s referencing contemporary music and those beyond their 50s ambivalent about exercise music. It is possible that the suggestion of era-specific exercise music arises from interviews with exercise-to-music instructors: Priest and Karageorghis (2008) found instructors (4 of their 13 participants) wanted those in their class to be familiar with the music they selected, which may have resulted in them using the many commercially-available era-specific aerobics class compilations. Class-instructors’ use of era-specific music may be satisfying the 'grouper' who wants to use music as a 
shared reference to connect with those exercising around them. The class environment, with its group ethos, contrasts with the often more individual nature of gym exercise.

The aural environment of the gym was not viewed positively by the participants here, with personal music players used to override broadcast music. This corresponds with Humpel et al.'s findings that the aesthetics of the environment were identified as an important factor in long-term physical activity (2002). Nevertheless, there was no suggestion among participants here that the gym’s music led to less frequent exercise; rather, it was dealt with by a request to reduce the volume or by listening to something else. Social support was important as an environmental feature for the socialisers but not for the workers within the context of the gym itself, contrasting somewhat with McAuley et al.’s study (2003) which found social support to be central to exercise behaviour. This raises the question of how the participants here were utilising the music they were listening to, and whether it was perceived as another type of support, perhaps through associations beyond its function as upbeat music suitable for exercise. There is clearly scope here for further research to gain a greater understanding of the process of choosing and using music during exercise.

Several participants used the term 'upbeat' to refer to their preferred exercise music, and the same term was used by interviewees discussing exercise in Bull’s 2007 iPod study and Heye and Lamont's 2010 paper. Dance music, which has a tempo of around 130-140bpm was referenced as particularly suitable for cardiovascular activity. This appears to support Karageorghis and Priest's observation in their 2012 review that tempi of 125-140bpm suit non-synchronous exercise: the nature of gyms, where many different activities are undertaken in the same room, means that background music should not be selected for synchronising. Only one participant reported synchronising movement to the tempo of the music on his listening device, and this had arisen 
accidentally. This is in contrast to choreographed exercise to music classes, where synchronising is central to the activity.

The study has some limitations: it was carried out at a single gym, and findings relate to the sample and to the environment, where the usual music played is a radio station featuring recent chart hits. Other gyms may be operating music policies which are more popular with members, or have memberships which have a younger age profile, in which case responses might be different. The interviewees were members who had the time available to take part, and this convenience sample may have omitted those with more work and/or family commitments, who may have been using music in other ways to the sample. Nevertheless, the study results show novel findings which are worthy of further research.

This study expands the knowledge of how people use music in exercise, particularly regarding selecting music from one’s youth: in this sample, unlike previous research, the intrinsic qualities of the music were more important than associations (again, this points to differences between music use in the gym and in exercise class environments).

Furthermore, the findings suggest strategies for increasing participation, such as emphasising social benefits to retirees. The success of gym visits as satisfying a need for routine and social interaction among retirees presents opportunities to promote physical activity among older cohorts, when exercise frequency tends to decline (Health and Social Care Information Centre, 2010). By drawing attention to these benefits, and encouraging interaction, the challenge of maintaining fitness in the later years might be addressed by the fitness profession. However, for the gym environment to appeal to older exercisers and for conversation to be practical, music policies at gyms need to incorporate careful attention to volume levels. 
Technology enabling participants to access their preferred exercise music was frequently referred to, and it may be possible to develop interventions using such technology to enhance the exercise experience and boost adherence. For example, BattRawden and DeNora (2005) describe a project where participants shared preferred music for enhancing wellbeing using CDs, and a similarly-structured project for sharing exercise music through MP3s may help promote engagement. It must also be recognised that music dissemination technologies are undergoing rapid change, and that practices among gym members may also change as devices become more sophisticated, and as the 'Walkman generation' reaches maturity. In this study, participants in their fifties were keen to listen to their own devices. In ten years, it is possible that they will still wish to do so, and that the socialisers identified in this study were less engaged with music players because they were in their thirties at the time personal listening devices first emerged, and maybe engaged with portable music less.

Overall, the study presents a useful picture of the range of ways in which people use exercise and music to benefit their day-to-day lives, investigating questions with participants representing populations that have been largely neglected in the literature. The findings provide a basis for further exploration of exercise take-up and adherence, examining how these might be addressed through acknowledging needs of the exercising and potentially-exercising public. It recognises the range of backgrounds and life-stages, identifying characteristics in motivation and exercise behaviour which seem to relate to the individual's demographic profile, and offers potential to increase exercise among the general population by taking these into account.

The authors would like to thank XXX XXX, the Manager at XXXXXX Leisure Complex and members of the gym for their kind help with this research. 


\section{References}

Ajzen, I. ,1991. The Theory of Planned Behaviour. Organizational Behavior and Human Decision Processes, 50, 179-211.

Barnett, A., Smith, B., Lord, S., Williams, M., and Baumand, A., 2003. Communitybased group exercise improves balance and reduces falls in at-risk older people: a randomised controlled trial. Age and Ageing, 32, 407-414.

Batt-Rawden, K., and DeNora, T., 2005. Music and informal learning in everyday life. Music Education Research, 7 (3), 289-304.

Beck, F., Gillison, F., and Standage, M., 2010. A theoretical investigation of the development of physical activity habits in retirement. British Journal of Health Psychology, 15, 663-679.

Becker, N., Chambliss, C., Marsh, C., and Montemayor, R., 1995. Effects of mellow and frenetic music and stimulating and relaxing scents on walking by seniors. Perceptual and Motor Skills, 80, 411-415.

Bharani, A., Sahu, A., and Mathew, V., 2004. Letter to the Editor: Effect of passive distraction on treadmill exercise test performance in healthy males using music. International Journal of Cardiology, 97, 305-6.

Bishop, D., Karageorghis, C., and Loizou, G., 2007. A grounded theory of young tennis players' use of music to manipulate emotional state. Journal of Sport and Exercise Psychology, 29, 584-607.

Braun, V., and Clarke, V., 2006. Using thematic analysis in psychology. Qualitative Research in Psychology, 3, 77-101.

Bull, M., 2007. Sound Moves: iPod culture and urban experience. Abingdon, Oxon: Routledge.

Cepeda, M., Carr, D., Lau, J., and Alvarez, H., 2006. Music for pain relief (Review). Cochrane Database of Systematic Reviews, 9 April 2006

Crust, L., and Clough, P., 2006. The influence of rhythm and personality in the endurance response to motivational asynchronous music. Journal of Sports Sciences, 24 (2), 187-195.

Deslandes, A., et al., 2009. Exercise and Mental Health: Many Reasons to Move. Neuropsychobiology, 59, 191-198.

Donaghy, M. (2007) Exercise can seriously improve your mental health: Fact or fiction? Advances in Physiotherapy, 9, 76-88. 
Edworthy, J., and Waring, H., 2006. The effects of music tempo and loudness level on treadmill exercise. Ergonomics, 49 (15), 1597-1610.

Elliott, D., Carr, S., and Orme, D., 2005. The effect of motivational music on submaximal exercise. European Journal of Sport Science 5 (2), 97-106.

Fox, K., 1999. The influence of physical activity on mental well-being. Public Health Nutrition, 2 (3a), 411-418.

Health and Social Care Information Centre, 2010. Statistics on obesity, physical activity and diet, England 2010 [online]. Available from:

https://catalogue.ic.nhs.uk/publications/public-health/obesity/obes-phys-actidiet-eng-2010/obes-phys-acti-diet-eng-2010-rep.pdf (accessed 3 Jan 2014).

Heye, A., and Lamont, A., 2010. Mobile listening situations in everyday life: The use of MP3 players while travelling. Musicae Scientiae, 14 (1), 95-120.

Hodgetts, W., Szarko, R., and Rieger, J., 2009. What is the influence of background noise and exercise on the listening levels of iPod users? International Journal of Audiology, 48, 825-832.

Holbrook, M., and Schindler, R., 1989. Some exploratory findings on the development of musical tastes. Journal of Consumer Research, 16, 119-124.

Humpel, N., Owen, N., and Leslie, E., 2002. Environmental Factors Associated with Adults’ Participation in Physical Activity: A Review. American Journal of Preventive Medicine, 22 (3), 188-199.

Karageorghis, C., and Priest, D.-L., 2012. Music in the exercise domain: a review and synthesis (Part II). International Review of Sport and Exercise Psychology, 5 (1), 67-84.

Karageorghis, C., et al., 2009. Psychophysical and Ergogenic Effects of Synchronous Music During Treadmill Walking. Journal of Sport and Exercise Psychology 31, 18-36.

Karageorghis, C., Priest, D.-L., Terry, P., Chatzisarantis, N., and Lane, A., 2006. Redesign an initial validation of an instrument to assess the motivational qualities of music in exercise: The Brunel Music Rating Inventory 2. Journal of Sports Sciences, 24 (8), 899-909.

Karageorghis, C., Terry, P., and Lane, A., 1999. Development and initial validation of an instrument to assess the motivational qualities of music in exercise and sport: The Brunel Music Rating Inventory. Journal of Sports Sciences, 17, 713-724. 
Lamont, A., and Webb, R., 2010. Short- and long-term musical preferences: what makes a favourite piece of music? Psychology of Music, 38, 222-241.

McAuley, E., Jermoe, G., Elavsky, S., Marquez, D., and Ramsey, S., 2003. Predicting long-term maintenance of physical activity in older adults. Preventive Medicine, 37, 110-118.

Myers, J., 2008. The Health Benefits and Economics of Physical Activity. Current Sports Medicine Reports, 7 (6), 314-316.

North, A., 2010. Individual differences in musical taste. American Journal of Psychology, 123 (2), 199-208.

Potteiger, J., Schroeder, J., and Goff, K., 2000. Influence of music on ratings of perceived exertion during 20 minutes of moderate intensity exercise. Perceptual and Motor Skills, 91, 848-854.

Powell, K., Paluch, A., and Blair, S., 2011. Physical Activity for Health: What Kind? How Much? How Intense? On Top of What? Annual Review of Public Health, 32, 349-365.

Priest, D.-L., and Karageorghis, C., 2008. A qualitative investigation into the characteristics and effects of music accompanying exercise. European Physical Education Review, 14 (3), 347-366.

Prochaska, J., and DiClemente, C., 1982. Transtheoretical Therapy: Toward a More Integrative Model of Change. Journal of Counselling and Clinical Psychology, 51 (3), 390-395.

Schwarzer, R., 2008. Modeling Health Behavior Change: How to Predict and Modify the Adoption and Maintenance of Health Behaviors. Applied Psychology: An International Review, 57(1), 1-29.

Sherwood, N., and Jeffery, R., 2000. The Behavioural Determinants of Exercise: Implications for Physical Activity Interventions. Annual Review of Nutrition, 20, 21-44.

Tenenbaum, G., et al., 2004. The effect of music type on running perseverance and coping with effort sensations. Psychology of Sport and Exercise, 5, 89-109.

Terry, P., and Karageorghis, C., 2006. Psychophysical Effects of Music on Sport and Exercise: An Update on Theory, Research and Application. In: Katsikitis, M., ed. Psychology Bridging the Tasman: Science, culture and practiceProceedings of the 2006 Joint Conference of the Australian Psychological 
Society and the New Zealand Psychological Society, Melbourne: Australian Psychological Society, 415-419.

Waterhouse, J., Hudson, P., and Edwards, B., 2010. Effects of music tempo upon submaximal cycling performance. Scandinavian Journal of Medicine and Science in Sports, 20, 662-669. 